\title{
Evaluation of the temporal variations of groundwater storage and its interactions with climatic variables using remotely sensed data
}

\author{
Behnam Khorrami ${ }^{1}$ and Orhan Gunduz ${ }^{2}$ \\ ${ }^{1}$ Dokuz Eylul Universitesi \\ ${ }^{2}$ Dokuz Eylül University
}

July 13, 2020

\begin{abstract}
Monitoring of the fluctuations of groundwater storage is particularly important in arid and semi-arid regions where water scarcity brings about various challenges. Remote sensing data and techniques play a preponderant role in developing solutions to environmental problems. Emergence of GRACE satellites have eased the remote monitoring and evaluation of groundwater resources with an unprecedented precision over large scales. Within the scope of the current study, the latest release of GRACE Mascon's dataset as well as GLDAS models of Noah and CLSM were integrated to extract groundwater storage anomalies (GWSA) over Turkey. The temporal interactions of the estimated GWSA with the climatic variables of precipitation and temperature (derived from the reanalysis datasets of CHELSA and FLDAS, respectively) were investigated statistically. The results suggest the there is a descending trend for TWSA and GWSA over Turkey with a total loss of 11 and $6 \mathrm{~cm}$ respectively. The statistical analysis results also indicate that the monthly variations of GWS over Turkey are highly correlated with precipitation and temperature at 2-month lag. The analysis of the climatology (long-term) values of monthly GWSA, precipitation and temperature also revealed high agreement between the variables.
\end{abstract}

\section{Introduction}

Surface and subsurface water resources are among the world's most precious assets, which require highest priority especially in arid/semiarid areas where the water supply is not enough to sustain human water needs. Thus, it is essential to manage these resources to guarantee the water sustainability. Terrestrial Water Storage [TWS] is one of the components of the hydrological cycle with a pivotal role in global and regional climate systems (Śliwińska, Birylo, Rzepecka \& Nastula, 2019). Precise knowledge about the variations of TWS is very important for climatologists and hydrologists for assessing the availability of water and understanding the changing climate patterns over time (Tangdamrongsub et al. 2020). Ground Water Storage [GWS] comprises the subsurface portion of TWS and stands for the water available among the pore spaces beneath the ground (Rahaman, Thakur, Kalra \& Ahmad 2019). With an estimated storage of $96 \%$ of the world's readily available liquid fresh water, GWS is critical for supporting the water requirements in domestic, agricultural and industrial sectors all around the world (Feng et al., 2013; Taylor et al., 2013; Ülker, Ergüven \& Gazioğlu2018).

The water resources of Turkey suffer heavy pressure in terms of quality and quantity because of the rapid population growth and industrialization as well as the impacts of climate change and the morpho-topological characteristics of the streams and rivers throughout the country (Croitoru, Divrak, Xie \& Arikan 2016). The available water in Turkey is expected to shrink from $1519 \mathrm{~m}^{3}$ per capita to $1120 \mathrm{~m}^{3}$ per capita by 2030 due to the anthropogenic and natural factors (DSI, 2015). Groundwater is a critical water resource for Turkey because of the fast social and economic growth of the country, which requires establishment of an adequate management and monitoring network with the focus on the sustainability of groundwater aquifers (Apaydin, 2011). However, overexploitation of groundwater aquifers in Turkey is a common problem causing 
an alarming situation in some regions with regards to declining water tables and increasing extraction costs. Unfortunately, as groundwater level data is not widely available spatially and temporally, it is difficult to present a realistic and unbiased picture of the situation (FAO, 2016).

The direct in-situ measurements of TWS is not common. In addition, the challenges and restrictions associated with the traditional monitoring approach of GWS (such as limited monitoring networks and incomplete temporal resolutions) pushes scientists and researchers into using remote sensing data collections and management tools and techniques particularly for regional studies. Remote sensing satellites have been providing useful data for the scientific community mostly at global scales. Gravity Recovery and Climate Exchange [GRACE] Program is the first remote sensing mission of its kind administrated by NASA. Since 2002, GRACE program has been providing gravitational pull signals, which are later converted into TWS estimations. In this study, the authors aim at monitoring the temporal variations of different hydro-climatic variables (including Soil Moisture Storage [SMS], Snow Water Equivalent [SWE], Terrestrial Water Storage [TWS], Groundwater Storage [GWS], Precipitation [P] and Temperature [T]) over Turkey based on GRACE and other remotely sensed data with the focus on obtaining significant relations between climatic variables and groundwater storage anomalies [GWSA]. The authors also aim to assess the impacts of climatic variables on the variations of groundwater storage over Turkey.

\section{Site Description}

Turkey is located between $25^{\circ} 38^{\prime}$ to $44^{\circ} 48^{\prime}$ East and $35^{\circ} 48^{\prime}$ to $42^{\circ} 6^{\prime}$ North [Figure 1] straddling Eastern Europe and Western Asia. Turkey is known for its diverse topography with different terrain features. The majority of the country is occupied by high mountains, East Anatolian Highlands in the East, Black Sea Mountain Range in the North, Taurus Mountains in the South, and the Anatolian Plateau in the center (Nistor and Man, 2019). While the general climate of Turkey is known to be of semi-arid type (Apaydin, 2011), the geographical characteristics of the country such as proximity to large water bodies and diverse topographical features create different subclimatic patterns in different regions of Turkey where coastal areas experience milder climates whereas hot summers and cold winters describe the dominant climate of the central Anatolian plateau (Sensoy, Demircan, Ulupınar \& Balta, 2008). Although the climatic parameters of temperature and precipitation vary from region to region, official statistics of the Meteorological Service indicates that the mean annual temperature and the total annual precipitation of Turkey is calculated to be $11.9{ }^{\circ} \mathrm{C}$ and 391.9 mm respectively (MGM, 2020).

\section{Please insert Figure 1 here.}

\section{Data Collection and Methodology}

Remote sensing data products for the hydrological purposes include a variety of data offered by different satellite and data modelling and assimilation missions. The gravimetric measurements done by GRACE satellites and modelled data products such as GLDAS and FLDAS are among the most interested data sources for hydrologists. In this study, the required data were acquired from five data sources. The hydrologic variables (TWS, GWS, SMS and SWE) were extracted from GRACE satellites and GLDAS data models. CHELSA and FLDAS mission outputs were used as a data sources for climatic variables (precipitation and temperature), respectively. A brief information upon the data used in the current study is given in Table 1.

Table 1. Specifications of the datasets used in the study

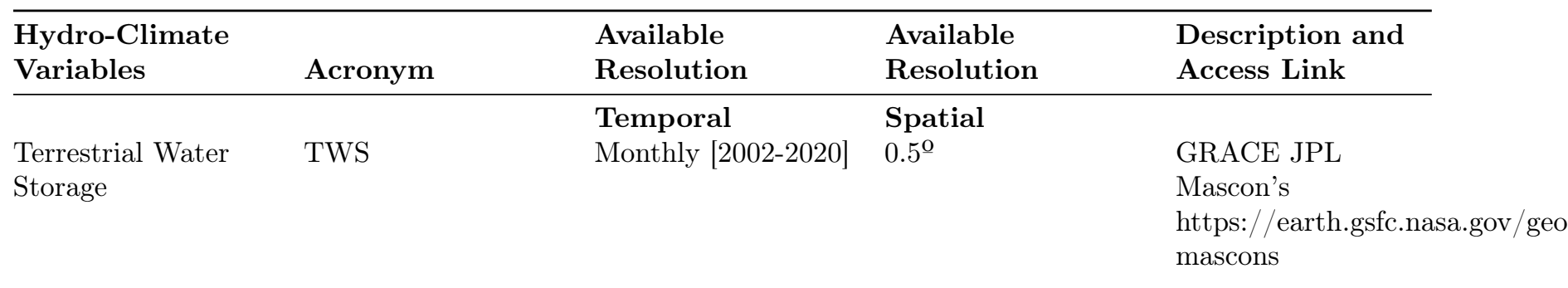




\begin{tabular}{|c|c|c|c|c|}
\hline $\begin{array}{l}\text { Hydro-Climate } \\
\text { Variables }\end{array}$ & Acronym & $\begin{array}{l}\text { Available } \\
\text { Resolution }\end{array}$ & $\begin{array}{l}\text { Available } \\
\text { Resolution }\end{array}$ & $\begin{array}{l}\text { Description and } \\
\text { Access Link }\end{array}$ \\
\hline $\begin{array}{l}\text { Groundwater } \\
\text { Storage }\end{array}$ & GWS & Daily [1948-2014] & $0.25^{\mathrm{O}}$ & $\begin{array}{l}\text { GLDAS_- } \\
\text { CLSM025_D } \\
\text { https://disc.gsfc.nasa.gov/data }\end{array}$ \\
\hline $\begin{array}{l}\text { Soil Moisture } \\
\text { Storage }\end{array}$ & SMS & Monthly [2000-2019] & $0.25^{\mathrm{o}}$ & $\begin{array}{l}\text { GLDAS_- } \\
\text { NOAH025_M } \\
\text { https://disc.gsfc.nasa.gov/data }\end{array}$ \\
\hline $\begin{array}{l}\text { Snow Water } \\
\text { Equivalent }\end{array}$ & SWE & Monthly [2000-2020] & $0.25^{\mathrm{o}}$ & $\begin{array}{l}\text { GLDAS_- } \\
\text { NOAH025_M } \\
\text { https://disc.gsfc.nasa.gov/data }\end{array}$ \\
\hline Precipitation & $\mathrm{P}$ & Monthly [1901-2016] & $0.0083^{\mathrm{o}}$ & $\begin{array}{l}\text { CHELSAcruts } \\
\text { http://chelsa- } \\
\text { climate.org }\end{array}$ \\
\hline Temperature & $\mathrm{T}$ & Monthly [1981-2020] & $0.1^{\mathrm{o}}$ & $\begin{array}{l}\text { FLDAS_-} \\
\text { NOAH01_C_GL_- } \\
\text { M } \\
\text { https://earthdata.nasa.gov/ }\end{array}$ \\
\hline
\end{tabular}

As given in Table1, data are of different spatial and temporal resolutions. The basic data source here is GRACE TWSA outputs. Accordingly, other variables were re-gridded using bilinear interpolation technique to ensure the spatial consistency with TWSA data. The bilinear algorithm performs the calculations in both directions (Miao et al, 2018) with the aid of the DNs (Digital Numbers) of the four adjacent cells of each individual pixel of the given imagery. As a result of interpolation, the new imageries were resampled to the grid size of half a degree to resemble the resolution of GRACE dataset. The advantage of re-gridding to the coarser resolution is to guarantee the accuracy of the comparisons of the values derived from different data sources restricting the influences of finer scale noises (Ljungqvist et al, 2019).

The interactions between groundwater storage fluctuations and climatic variables were evaluated using the linear regression method. The correlation and regression coefficients at the significance level of $95 \%$ and 0.5-degree resolution were used to show the strength of the relationships of P-GWSA and T-GWSA over the study area at monthly scale.

\section{Groundwater Storage Isolation from GRACE Measurements}

Since its launch in March 2002, the Gravity Recovery and Climate Experiment [GRACE] satellite mission has provided an alternative and complementary data source for monitoring large-scale mass changes of Earth's system on different time scales with unprecedented accuracy (Tapely et al, 2004). GRACE is comprised of two identical satellites orbiting the same orbital plane of the earth with an estimated distance of 220 $\mathrm{km}$ at an altitude of $500 \mathrm{~km}$ (Tapely et al, 2004). It is a unique satellite mission from the viewpoint of its ability to deliver direct estimated measurements of the variations of groundwater storage of the earth. It is based on the principle of the relationship between the earth's gravitational pull and mass changes at the earth's surface from which, the TWS variations of the earth can be inferred from using the monthly variations of the gravity field measurements (Hu et al, 2019). Mass movements of the earth bring about the differences in the distance between the two satellites, which are then translated into water storage changes and reported as TWSA ( NASA Facts, 2003). The processing (filtering, truncation, scaling and smoothing) done traditionally on the original signals of GRACE cause decreases in the ratio of signal to noise $(\mathrm{S} / \mathrm{N})$ of the data. The newly released version of GRACE products, called mass concentration (mascon), does not need scaling, thus, the uncertainties are less than the original spherical harmonics and the accuracy level is higher (Xu, Chen, Zhang \& Chen, 2019).

Terrestrial Water Storage (TWS) is a hydrological component describing the different components of the 
water cycle. The following equation is used to define the anomalies of TWS over a given area.

$T W S=G W S+S W E+S M S+S W S[1]$

where GWS, SWE, SMS and SWS represent groundwater storage, snow water equivalent, soil moisture storage and surface water storage, respectively. GWS is the main component of TWS that shows the amount of water stored inside the aquifers beneath the ground. The variations in GWS can be isolated from the integral TWSA based on the following equation.

$G W S=T W S-[S W E+S M S+S W S][2]$

Thus, SWE, SMS and SWA measurements are required for GWS isolation from GRACE TWSA. According to Frappart and Ramillien (2018) in arid and semi-arid regions of the world where TWS is limited to soil water storage, the simplest cases to estimate groundwater changes is to ignore surface water storage. Thus, like many previous studies, the GWS is isolated from GRACE TWS using SWE and SMS variables (Yang, Wang, Chen, Chen \&Yu, 2015; Deng and Chen, 2017; Hu et al, 2019) as follows:

$G W S=T W S-[S W E+S M S][3]$

\section{Global Land Data Assimilation System [GLDAS] Model}

The Global Land Data Assimilation System (GLDAS) is a data assimilation mission of the National Oceanic and Atmospheric Administration [NASA] and the National Centers for Environmental Prediction to simulate different hydro-climatic variables at a higher resolution. Remotely sensed data and in-situ observations are integrated using sophisticated land surface modeling tools and data assimilation techniques (Ramillien, Famiglietti \& Wahr, 2008; Rodell, Velicogna \& Famiglietti, 2009) culminating in a very useful dataset of land surface states and fluxes especially in hydrology and climatology (Sliwinska, Birylo, Rzepecka, \& Nastula, 2019). GLDAS mission simulates the hydro-climatic variables under different land surface models (LSMs) including the Community Land Model [CLM], Variable Infiltration Capacity [VIC] Model, Noah Model, Mosaic Model and Catchment Land Surface Model [CLSM] (Rahaman et al, 2019) with various temporal resolutions ranging from an hour to a month and spatial resolutions from 0.1 to 1.25 degrees (Hu et al, 2019). GLDAS is the most favorable data source to be used for deriving GWSA from GRACE measurements. In this study, the latest version of GLDAS-Noah data model [Noah-2.1 monthly 0.25 degree] was used to deduce the SMS and SWE variables required for GWS isolation. Soil Moisture is modelled in four different depths [0-10, 10-40, 40-100 and 100-200 cm] by GLDAS models. The aggregation of these layers were done to get the SMS variable for the study area. Catchment Land Surface Model [CLSM] is the only LSM model to simulate TWS and GWS values individually. The simulated GWS by GLDAS_CLSM model was also used to compare with the GRACE based GWS variations.

\section{Precipitation Data from CHELSA Model}

A majority of applications in environmental and ecological sciences take the benefit of high-resolution climatic datasets. These improved resolutions are mostly available at local scales; however, some advanced approaches have made it possible to generate a variety of variables at higher resolutions on a global scale. The CHELSA [Climatologies at High Resolution for The Earth's Land Surface Areas] is a sort of reanalysis data source, which produces downscaled model outputs of climatic variables e.g. precipitation and temperature at 30 arc sec resolution (Karger et al. 2017). CHELSA applies the statistical downscaling technique on atmospheric temperature to generate high-resolution temperature data layers. The precipitation algorithm incorporates orographic predictors including wind fields, valley exposition, and boundary layer height with a subsequent bias correction (Karger \& Zimmermann, 2019). CHELSAcruts consists of monthly climate datasets including mean monthly maximum temperatures, mean monthly minimum temperatures, and monthly precipitation sums for the period of 1901 to 2016. More information about the CHELSA is available in Karger \& Zimmermann [2019]. In this study, the CHELSA data model was used as the high-resolution data source for precipitation.

\section{Temperature Data from FLDAS Noah Model}


FLDAS is the Famine Early Warning Systems Network [FEWS NET] Land Data Assimilation System. With the use of meteorological inputs such as temperature, rainfall, humidity and wind, FLDAS generates multimodel and multi-forcing estimations of hydro-climatic conditions such as soil moisture, evapotranspiration, and runoff (McNally et al, 2017). FLDAS offers monthly hydro-climatic variables such as rainfall, evaporation, air and soil temperature etc. modelled by two land surface models: Noah3.3 [0.1-degree resolution] and VIC4.2.1 [0.25-degree resolution]. In the current study, the FLDAS Noah3.3 data model was used as the high-resolution data source for temperature.

1. Results and Discussion

2. Temporal Variations of the GLDAS Based SMS and SWE

The GLDAS mission products are offered as temporal estimations of the variables of interest. Since the GRACE deliveries are in the form of anomaly estimations, the auxiliary variables SMS and SWE should be transformed into anomalies to be in harmony with GRACE TWSA measurements. GRACE gravity records are translated into anomalies of terrestrial water storage based on the mean estimations of TWS from 20042009. In this study, the anomalies of soil moisture storage and snow water equivalent received from GLDAS Noah model outputs were calculated according to this baseline. Figures 2 and 3 show the variations of the mean zonal values of SMS and SWE over Turkey, respectively.

\section{Please insert Figure 2 here}

\section{Please insert Figure 3 here}

According to the graphs of Soil Moisture Storage Anomalies (SMSA) and Snow Water Equivalent Anomalies (SWEA), it is noticed that the soil moisture storage over Turkey manifests a sharp change in a monthly way with a total descending trend from the Jan 2003 to the Dec 2016. The max soil moisture storage $(7.08 \mathrm{~cm})$ was recorded in Feb 2010 while the min amount $(-7.27 \mathrm{~cm})$ was recorded in Feb 2014. The SWEA, however, shows a relatively ascending trend through the same period. The monthly variations in the snow storage over Turkey is not so dramatic except 3 points where the maximum (Mar 2003 and 2012) and minimum (Feb 2014) storages happened.

\section{Temporal Variations of TWSA and GWSA}

GRACE gridded data provides Terrestrial Water Storage Anomalies estimated directly from the space based on the variations in the gravitational pull of the earth. This integrated TWSA values shall be disintegrated into the ingredients with the aid of auxiliary data from other resources, mainly modelled data. The GRACEGWSA fluctuations isolated from TWSA using GLDAS based SMS and SWE variations. The temporal fluctuations of TWSA and GWSA are shown in figures 4 and 5, respectively. The graphs indicate a descending trend for both TWSA and GWSA over Turkey for the time period between 2003 and 2016. The maximum and minimum variations in TWSA occurred in Sep 2008 and Mar 2004 as 18.5 and $-17.8 \mathrm{~cm}$, respectively. According to GWSA graph, the max loss of the storage of groundwater happened in Oct 2014 with an amplitude of almost $-19.5 \mathrm{~cm}$. The total loss of TWSA and GWSA during the study period [from Jan 2003 to Dec 2016] was found to be approximately 11 and $6 \mathrm{~cm}$, respectively.

\section{Please insert Figure 4 here}

\section{Please insert Figure 5 here}

Among the different land surface models offered by GLDAS mission, the Catchment Land Surface Model (CLSM) is the only one that models groundwater storage estimations. The modelled GWS estimations were extracted from CLSM data model outputs and then the anomalies of the storage were calculated based on the same baseline used for GRACE dataset. Figure 6 illustrates the comparison of the GRACE GWSA and CLSM GWSA estimations from 2003 to 2014 over Turkey. The modelled GWSA seems not to be in harmony with the GRACE estimations. The Correlation coefficient between GRACE and CLSM based GWSA was found to be 0.21 . This low agreement seen between satellite and modelled GWSA values results from the 
uncertainties associated with the GLDAS estimations of groundwater storage, which is a restricting aspect for the application of these estimations.

Please insert Figure 6 here

Please insert Figure 7 here

\section{Temporal Variations of Precipitation and Temperature}

The temporal variations of climatic variables of the total monthly precipitation [Figure 7] and mean monthly temperature [Figure 8] over Turkey were extracted from gridded CHELSA and FLDAS outputs, respectively. According to the graphs, there is a slight rise in the trends of both precipitation and temperature values from 2003 to 2016. The interaction of climatic variables and variations of groundwater storage were analyzed in different time lags. The best fit was found between GWSA and 2-month-lagged precipitation and temperature with the correlation coefficient of 0.615 and 0.867 , respectively. Figures 9 and 10 show the monthly interactions of GWSA and climatic variables over Turkey.

Please insert Figure 7 here

Please insert Figure 8 here

Please insert Figure 9 here

Please insert Figure 10 here

For the general climatology analysis of GWSA and the climatic variables in the study area, the average of the long-term monthly values of GWSA, precipitation and temperature were calculated and plotted to evaluate the long-term monthly interactions of each variable with GWSA. The temporal interactions of climatology values of GWSA and climatic variables of precipitation and temperature in 2-month lagged time step are illustrated in figures 11 and 12. The correlation between climatology variables was found to be the highest in 2-month lags for the study area. Figure 13 depicts the comparison of the mean annual correlations found between monthly GWSA and climatic variables. It is revealed that the variations of groundwater in the study area interacts more strongly with temperature. Therefore, it can be said that temperature increase plays a more dominant role on the variations of groundwater storage over Turkey. Summary of the regression statistics of the temporal values is shown in Table 2. According to the climatology graphs, it is understood that the least amount of groundwater storage $[-11.5 \mathrm{~cm}]$ happens on August, which corresponds to the least amount of precipitation and highest temperature for the general prevailing climatic conditions in Turkey. The max storage of groundwater $[10.76 \mathrm{~cm}]$, on the other hand, occurs on February, which correspond the mid-winter conditions with high precipitation and infiltration values.

Please insert Figure 11 here

Please insert Figure 12 here

Please insert Figure 13 here

Table 2. Regression analysis results of the interactions between GWSA and 2-month lagged monthly and climatology precipitation and temperature

\begin{tabular}{lllll}
\hline GWSA & Correlation [R] & Regression $\left[\mathbf{R}^{2}\right]$ & Standard Error & $\begin{array}{l}\text { Regression } \\
\text { Equation }\end{array}$ \\
\hline $\mathbf{P}$ [Monthly] & 0.610 & 0.372 & 0.062 & $\mathrm{Y}=-9.8622+$ \\
$\mathbf{T}$ [Monthly] & -0.867 & 0.752 & 0.039 & $\begin{array}{l}\mathrm{Y}=9.7514- \\
\text { [Anomalies] }\end{array}$ \\
& 0.615 & 0.378 & $0.911 \mathrm{x}$ \\
$\mathbf{P}$ & & & $\mathrm{Y}=-0.6798+$ \\
& & & & $0.1902 \mathrm{x}$
\end{tabular}




\begin{tabular}{lllll}
\hline GWSA & Correlation $[\mathbf{R}]$ & Regression $\left[\mathbf{R}^{2}\right]$ & Standard Error & $\begin{array}{l}\text { Regression } \\
\text { Equation }\end{array}$ \\
\hline T [Anomalies] & -0.866 & 0.750 & 0.039 & $\mathrm{Y}=-7.75 \mathrm{E}-05-$ \\
$\mathbf{P}$ [Climatology] & 0.906 & 0.821 & 0.141 & $\begin{array}{l}\mathrm{Y}=-15.7517+ \\
\text { T [Climatology] }\end{array}$ \\
& -0.969 & 0.939 & & $0.3012 \mathrm{x}$ \\
& & & 0.082 & $\mathrm{Y}=8.9169-$ \\
\hline
\end{tabular}

In Figure 14, the spatial illustration of extreme values of the hydro-climatic variables over the study area are given. According to the maps and based on the literature sources, it is revealed that the minimum variations of theses variables correspond to the general drought periods experienced in Turkey during 2007-2008 and 2013-2014 periods (Kurnaz, 2014), which reveals the accuracy of the used remotely sensed data sets in catching the exact fluctuations of the hydro climatic variables over Turkey. The extreme values extracted for the climatic variables of precipitation (in 2012 and 2015) and temperature (in 2006 and 2008) however, seem not to fully agree with the drought periods.

\section{Please insert Figure 14 here}

\section{Conclusions}

Water resources especially the groundwater are among the natural resources being subjected to ignorance by human communities around the world. The impacts of the climate change mostly in terms of reduced precipitation and increased temperatures accompanied by misuse and mismanagement of these resources contribute to great losses and in some cases resulted in irreversible impacts on surface and subsurface waters. The problem is especially more common in arid and semi-arid regions where there is a huge pressure on groundwater resources. The environmental impacts of the overuse of groundwater aquifers include the socio-economic losses in the form of increased exploitation costs for water provision as well as the costs for making up for the environmental damages and the challenges of migration etc. On the other hand, the losses imposed on the environment by the groundwater degradation vary from land subsidence, water quality degradation to drying up of the wells nearby.

Turkey is going to be one of the problematic countries in regard of water issues especially in near future. Some of the regions of the country especially the Aegean and Central Anatolian regions have been challenging with the groundwater depletion and its consequences during recent years. Taking into account the limitations of the traditional approaches for monitoring water resources particularly in large scales, the use of remote sensing technology has become popular and common among the scholars and decision makers as well in recent years especially with the emergence of GRACE satellites and the development of data modelling and assimilation systems. Taking the benefits of remotely sensed data, the variations of terrestrial water and groundwater storage over Turkey were analyzed in this study. The results suggested that the total trend of monthly TWSA and GWSA over Turkey is descending with a total decrease of 11 and $6 \mathrm{~cm}$ from 2003 to 2016, respectively. The interactions of the GWSA with climatic variables of precipitation and temperature were also studied. The results indicate that there is a good agreement between GWSA and climatic variables with 2 -month lag. The best correlation was found between climatology values of precipitation and temperatures and GWSA. The monthly statistics revealed that the impact of increased temperatures on the variations of groundwater storage over Turkey is much more evident compared to precipitation, which indicates that the evapotranspiration resulting from warm weather condition in the country controls the variations of GWS. However, the regression results show that the variations of GWS over Turkey can be modelled with high accuracy using the climatic variables. Findings of this study emphasized the overall feasibility of satellite and modelled datasets to study the large-scale fluctuations of hydro-climatic variables in at country or regional extends. 


\section{References}

Śliwińska, J., Birylo, M., Rzepecka, Z., \& Nastula, J. [2019]. Analysis of Groundwater and Total Water Storage Changes in Poland Using GRACE Observations, In-situ Data, and Various Assimilation and Climate Models. Remote Sensing, 11[24], 2949.

Tangdamrongsub, N., Han, S. C., Yeo, I. Y., Dong, J., Steele-Dunne, S. C., Willgoose, G., \& Walker, J. P. [2020]. Multivariate data assimilation of GRACE, SMOS, SMAP measurements for improved regional soil moisture and groundwater storage estimates. Advances in Water Resources, 135, 103477.

Rahaman, M. M., Thakur, B., Kalra, A., \& Ahmad, S. (2019). Modeling of GRACE-derived groundwater information in the Colorado River Basin. Hydrology, 6(1), 19.

Feng, W., Zhong, M., Lemoine, J. M., Biancale, R., Hsu, H. T., \& Xia, J. (2013). Evaluation of groundwater depletion in North China using the Gravity Recovery and Climate Experiment (GRACE) data and groundbased measurements. Water Resources Research, 49(4), 2110-2118.

Taylor, R. G., Scanlon, B., Döll, P., Rodell, M., Van Beek, R., Wada, Y., .. \& Konikow, L. (2013). Ground water and climate change. Nature climate change, 3(4), 322-329.

Ülker, D., Ergüven, O. \& Gazioğlu, C. [2018]. Socio-economic impacts in a Changing Climate: Case Study Syria, International Journal of Environment and Geoinformatics [IJEGEO], Vol. 5[1]: 84-93.

Croitoru, L., Divrak, B., Xie, J. \& Arikan, E. [2016] Valuing Water Resources in Turkey: A Methodological Overview and Case Study. The World Bank, Washington DC.

DSI [2015]. Official data of DSİ. Water statistical data. General Directorate of State Hydraulic Works. Retrieved March 7, 2015, http://www.dsi.gov.tr/dsi-resmi-istatistikler. (Original in Turkish)

FAO [2016]. Turkey Water along the Food Chain. Retrieved on 01.05.2020 from http://www.fao.org/3/ai5991e.pdf

Apaydin, A. [2011]. Groundwater legislation in Turkey: problems of conception and application. Water international, 36[3], 314-327.

Nistor, M. M., \& Man, T. C. [2019]. Water availability variation under climate change in Turkey during 21st century. Carpathian J. Earth Environ. Sci, 14, 19-28.

Sensoy, S., Demircan, M., Ulupınar, U \& Balta, İ. [2008]. Türkiye İklimi, MGM web sitesi Url: http://www.mgm.gov.tr/FILES/iklim/turkiye_iklimi.pdf (Original in Turkish)

MGM [2020]. Turkish State Meteorological Service [MGM]. Official Statistics. Received on 05.03.2020 at: https://www.mgm.gov.tr/veridegerlendirme/il-ve-ilceler-istatistik.aspx.

Miao, Y., Song, D., Shi, W., Yang, H., Li, Y., Jiang, Z. \& Gu, W. [2018]. Application of the CLAHE Algorithm Based on Optimized Bilinear Interpolation in Near Infrared Vein Image Enhancement. In Proceedings of the 2nd International Conference on Computer Science and Application Engineering, pp. 1-6.

Ljungqvist, F. C., Seim, A., Krusic, P. J., González-Rouco, J. F., Werner, J. P., Cook, E. R., ... \& GarcíaBustamante, E. [2019]. European warm-season temperature and hydroclimate since 850 CE. Environmental Research Letters, 14(8), 084015.

Hu, Z., Zhou, Q., Chen, X., Chen, D., Li, J., Guo, M \& Duan, Z. [2019]. Groundwater Depletion Estimated from GRACE: A Challenge of Sustainable Development in an Arid Region of Central Asia. Remote Sensing, 11[16], 1908.

NASA Facts [2003]. Studying the Earth's Gravity from Space: The Gravity Recovery and Climate Experiment [GRACE]. Accessible from: https://eospso.nasa.gov/sites/default/files/publications/GRACE_Fact_Sh_Final.pdf 
Xu, L., Chen, N., Zhang, X., \& Chen, Z. [2019]. Spatiotemporal changes in China's terrestrial water storage from GRACE satellites and its possible drivers. Journal of Geophysical Research: Atmospheres, 124(22), 11976-11993.

Yang, T.; Wang, C.; Chen, Y.; Chen, X \& Yu, Z. [2015]. Climate change and water storage variability over an arid endorheic region. Journal of Hydrology, 529, 330-339.

Deng, H \& Chen, Y. [2017]. Influences of recent climate change and human activities on water storage variations in Central Asia. Journal of Hydrology, 544, 46-57.

Frappart, F., \& Ramillien, G. [2018]. Monitoring groundwater storage changes using the Gravity Recovery and Climate Experiment [GRACE] satellite mission: A review. Remote Sensing, 10[6], 829.

Ramillien, G., Famiglietti, J. S., \& Wahr, J. [2008]. Detection of continental hydrology and glaciology signals from GRACE: a review. Surveys in Geophysics, 29[4-5], 361-374.

Rodell, M., Velicogna, I., \& Famiglietti, J. S. [2009]. Satellite-based estimates of groundwater depletion in India. Nature, 460[7258], 999-1002.

Sliwinska, J., Birylo, M., Rzepecka, Z., \& Nastula, J. [2019]. Analysis of Groundwater and Total Water Storage Changes in Poland Using GRACE Observations, In-situ Data, and Various Assimilation and Climate Models. Remote Sensing, 11[24].

Karger, D.N., Conrad, O., Böhner, J., Kawohl, T., Kreft, H., Soria-Auza, R.W., ..., \& Kessler, M. [2017]. Climatologies at high resolution for the earth's land surface areas. Scientific Data 4, 170122.

Karger, D. N. \& Zimmermann, N. E. [2019]. Climatologies at High Resolution for the Earth Land Surface Areas CHELSA V1. 2: Technical Specification. Swiss Federal Research Institute WSL, Switzerland.

McNally, A., Arsenault, K., Kumar, S., Shukla, S., Peterson, P., Wang, S., \& Verdin, J. P. [2017]. A land data assimilation system for sub-Saharan Africa food and water security applications. Scientific Data, 4[1], $1-19$.

Kurnaz, L. (2014). Drought in Turkey. İstanbul Policy Center, Sabancı Üniversitesi-İstanbul. https://ipc.sabanciuniv.edu/Content/Images/CKeditorImages/20200323-16034017.pdf

\section{Data Availability Statement}

The data that support the findings of this study are available from the corresponding author upon reasonable request.

\section{Hosted file}

Figures.docx available at https://authorea.com/users/341914/articles/468794-evaluationof-the-temporal-variations-of-groundwater-storage-and-its-interactions-with-climaticvariables-using-remotely-sensed-data 